\title{
INFLUENCE OF HYBRID FILLERS ON MORPHOLOGICAL AND MECHANICAL PROPERTIES OF CARBOXYLATED NITRILE BUTADIENE RUBBER COMPOSITES
}

\section{K. ABITHA ${ }^{1}$, V. R. REMYA ${ }^{2}$, AJAY VASUDEO RANE ${ }^{3}$, SAINATH JADHAV $^{3}$ and RAGHVENDRA KUMAR MISHRA ${ }^{4}$}

${ }^{1}$ Department of Polymer Science and Rubber Technology

Cochin University of Science and Technology

Kerala

India

2Department of Chemistry

Devaswom Board Pampa College

Parumala, Pathanamthit

Mahatma Gandhi University

Kottayam, Kerala

India

${ }^{3}$ Centre for Green Technology

Institute of Chemical Technology

Centre of Excellence and Elite Status-Government of Maharashtra

Mumbai

India

e-mail: ajayrane2008@gmail.com

${ }^{4}$ Department of Chemistry

Indian Institute of Space Science and Technology

ISRO P.O., Thiruvananthapuram 695022

Kerala

India

Keywords and phrases: carboxylated NBR, nanoclay, dynamic mechanical analyzer, carbon black, nanocomposites.

Received November 19, 2015; Revised January 14, 2016

(C) 2016 Scientific Advances Publishers 


\begin{abstract}
The processing in addition to characterization of carboxylated nitrile butadiene rubber based nanocomposites is presented in this work. The outcome of nanoclay (NC) in black filled compounds is tinted. 20phr carbon black was used as standard in the entire studies while the nanoclay loading was varied from 2.5 to $10 \mathrm{phr}$. The effect of nanoclay loading on the cure properties of XNBR was studies by using Moving Die Rheometer (MDR). The studies showed that the adding up of nanoclay significantly affected the scorch time and cure time of the rubber nanocomposites. The storage stability of the rubber composites were moreover characterised using rheometer. The effect of curing temperature on the physical properties of the rubber nanocomposites were studied by curing the rubber compound at $140^{\circ} \mathrm{C}, 150^{\circ} \mathrm{C}$, and $160^{\circ} \mathrm{C}$. XRD and TEM studies were carried out for characterising the morphology of the rubber nanocomposites. The microstructure showed a mixture of intercalated and exfoliated clay structure in rubber matrix. The rubber nanocomposites were characterised for the mechanical properties including tensile strength, elongation at break, abrasion resistance, and dynamic mechanical properties. The studies showed that the tensile strength showed an increase of $62 \%$ compared to that XNBR with only $20 \mathrm{phr}$ carbon black at lower loading of nanoclay which further decreased at higher loading of NC. However, the dynamic modulus showed a steady increase with increase in NC loading.
\end{abstract}

\title{
1. Introduction
}

In the rubber industry, rubbers are mixed with diverse ingredients to improve the processing and properties such as tear strength, abrasion resistance, aging behaviour etc. Carbon black is a vital ingredient, which is used comprehensively to develop the mechanical properties and hardness of a rubber vulcanizate. Although the use of carbon black is predictable to attain the final properties in rubber compound, the everincreasing crude oil prices and greenhouse gasses concerns have forced both industry and researchers to find ways to minimize the use of this filler. One such approach is to develop rubber - carbon black - nanoclay hybrid nanocomposites, which allows a considerable reduction in carbon black loading. Polymer nanocomposites have careworn considerable attention in recent years. The advances in research on polymer nanocomposites have been recently reviewed by Ratna [1, 2]; Jordan et al. [3]; and Ray [4]; $\mathrm{Vu}$ et al. [5] studied the clay nanolayer 
reinforcement of cis-1,4-polyisoprene and epoxidized natural rubber. Sadhu and Bhowmick [6, 7] reported on the influence of processing parameters and effect of chain length of amine and nature of clay on styrene-butadiene rubber clay nanocomposites. Karger Kocsis and Wu [8] reported the research in the field of rubber/layered silicate nanocomposites elaborating their production methods, cure characteristics, mechanical properties and morphology. Akita and Hattori [9] reported the studies on processing of molecular composites by means of a precursor polymer for poly ( $p$-phenylene benzobisthiazole). Cho and Paul [10] considered melt compounding of Nylon 6 nanocomposites. Bhowmick and co-workers studied the effect of carbon black on properties of rubber/clay nanocomposites [11]. Black filled SBR nanoclay composites have been observed and formation of unique nanounits between the clay platelets and carbon black particles leading to a synergistic effect in improving the physical properties of rubber nanocomposites [12]. Praveen et al. [13] investigated the effect of rubber Mooney viscosity and polarity on the morphology and physical properties of millable polyurethane and bromobutyl rubber-clay nanocomposites. They have reported that the addition of nanoclay into the rubber can lead to a noteworthy enhancement in the mechanical and barrier properties as an outcome of incorporation of clay. A through literature survey reveals that there are less research reports on rubber-nanocomposites compared to the thermoplastic and thermoset resin based nanocomposites [14-18]. Rubber should be ideal polymer matrix to produce nanocomposites due to the following facts -first, amine compounds (used as low-molecular-weight intercalants/surfactants/ in organophilic layered silicates) act in sulphur curing rubber recipes as activators [19]. Thus, layered silicates intercalated by amine-compounds (containing primary, tertiary, and quaternary amines) may be involved in the sulphur-curing reactions. Second, rubbers are high molecular-weight polymers showing extremely high viscosities during melt compounding. Owing to the latter, high shear stresses may act locally on the layered silicate stacks, causing their shear 
and peeling apart and thus delamination of silicate layers [8]. To incorporate layered silicates in rubbers, the following routes are usually followed: solution blending (solvent-assisted techniques) [20-22], latex compounding (water assisted techniques) [23, 24], melt mixing (direct methods) [25]. The drawbacks of a solution intercalation method are the requirement of a suitable monomer/solvent or polymer/solvent pairs and the high costs associated with the solvents, their disposal, as well as their impact on the environment. Melt intercalation does not involve the use of any solvent. The melt-intercalation process involves annealing a mixture of the polymer and organically modified nanoclay above the softening point of the polymers, under shear. Whereas annealing, the polymer chains diffuse from the bulk polymer melt into the galleries sandwiched between the silicate layers foremost to the pattern of nanocomposites. This process has become the conventional way for the fabrication of polymer nanocomposites in years because it is simple, economical, environment friendly, and easy to implement in current polymer processing techniques.

\section{Experimental Results}

\section{Materials}

Krynac X 146 carboxylated butadiene - acrylonitrile terpolymer with Mooney viscosity $\mathrm{ML}(1+4) 100^{\circ} \mathrm{C}, 45 \pm 5 \mathrm{MU}$ and acrylonitrile content $32.5 \pm 1.5 \%$ was procured from Lanxess, Germany, Nanomer ${ }^{\circledR}$ I.30E Organically modified MMT clay modified with octadecyl amine, mean dry particle size (microns) 8-10, + 325 Mesh Residue, Specific gravity 1.71, mineral purity (\% min) 98.5 was procured from Nanocor Corporation, USA. High abrasion furnace black, HAF (N330) having iodine absorption No. $82 \pm 7 \mathrm{~g} / \mathrm{kg}$, DBP absorption No. $102 \pm 7 \mathrm{~m}^{3} / \mathrm{kg}$, nitrogen absorption specific area $103 \mathrm{~m}^{2} / \mathrm{kg}$, was procured from Philips Carbon Black Ltd. India. Other rubber chemicals were of analytical grade and were purchased from local suppliers. 


\section{Methods}

\section{Preparation of XNBR nanocomposites}

The mixing of XNBR and nanoclay (NC) was prepared on a two-roll mill. The incorporation of $\mathrm{NC}$ was done in the initial stages of the mixing, before the addition of other fillers. 2.5, 5, and 10phr clay loading was used. 20phr N330 carbon black was also added to all the compositions. After the NC addition, the compound was passed through tight nip (less than $1 \mathrm{~mm}$ ) 3-4 times. The optimum cure time (OCT) was determined at $150^{\circ} \mathrm{C}$ by using moving die rheometer (MDR 2000, Alpha Technologies, USA). The samples were moulded in the form of sheets by compression molding at $150^{\circ} \mathrm{C}$ at their respective optimum cure times.

\section{Characterizations}

\section{WAXRD studies on nanocomposites}

Wide-angle X-ray diffraction (XRD) at lower angular range was used to study the nature and dispersions of the clay in the filled samples. The XRD patterns were obtained by using a high resolution X-ray diffractometer XPert Pro (PANalytical) using monochromatic $\mathrm{CuK \alpha}$ radiation (wavelength $1.542 \mathrm{~A}$ ) at a $\theta$ scan rate of $1^{\circ}$ per minute, in the range $2^{\circ}-10^{\circ}$. Acceleration voltage of $40 \mathrm{kV}$ and beam current $30 \mathrm{~mA}$ were used. The $d$-spacing of the clay particles were calculated by using the Bragg's law. The samples used for XRD are flat test pieces cut from moulded sheets.

\section{TEM analysis}

JEOL JEM-2100 transmission electron microscope with lanthanum hexaborate filament was used (acceleration voltage of $200 \mathrm{kV}$ and beam current of $116 \mu \mathrm{A}$ ) for observing the morphology of XNBR nanocomposites. Samples were cut to $50 \mathrm{~nm}$ thin sections using Leica Ultracut ultra cryotom at $-60^{\circ} \mathrm{C}$. The cut samples were supported on a copper mesh before observation under microscope. 


\section{Mechanical properties}

Tensile specimens were punched out from the moulded sheets using ASTM Die- C. The tests were carried out as per the ASTM D - 412 methods in a Universal Testing Machine (Hounsfield 50K, UK) at a cross

head speed of $500 \mathrm{~mm} / \mathrm{min}$. Tensile properties reported here are the averages of five samples.

\section{Dynamic mechanical properties}

The dynamic mechanical thermal analysis was conducted using rectangular samples with dimensions $30 \mathrm{~mm} \times 10 \mathrm{~mm} \times 2 \mathrm{~mm}$ thick on DMA machine of GABO, Germany. Dynamic temperature sweep test were conducted at a frequency of $1 \mathrm{~Hz}, 0.05 \%$ strain, covering temperature ranges of -80 to $+50^{\circ} \mathrm{C}$ at a heating rate of $2^{\circ} \mathrm{C} / \mathrm{min}$.

\section{Results and Discussion}

\section{Curing characteristics}

The cure characteristics of the rubber nanocomposites were studied using a moving die rheometer at $150^{\circ} \mathrm{C}$. The respective cure times and maximum torque values are given in Table 1 .

\section{Effect of nanoclay}

The effect of $\mathrm{NC}$ on the cure characteristics of XHAF matrix is shown in Figure 1. The addition of $\mathrm{NC}$ to rubber matrix lead to a steady decrease in scorch time and optimum cure time (OCT). There was a decrease of $55 \%$ in scorch time and 51\% in OCT compared to the control XHAF. This can be explained by considering the mechanism of accelerated sulphur vulcanization in rubbers $[16,17,18]$. The amine compounds (used as low-molecular-weight intercalants/surfactants/ in organophilic layered silicates) act as activators in sulphur curing rubber recipes $[13,14]$. Thus, layered silicates intercalated by amine-compounds (containing primary, tertiary and quaternary amines) may be involved in the sulphur-curing reactions activating the cure process and thereby 
decreasing cure time. However, the maximum torque $\left(\mathrm{M}_{\mathrm{H}}\right)$ values increased as the loading of NC was increased from 2.5 to 5phr. Further addition of $\mathrm{NC}(10 \mathrm{phr})$ lead to decrease in $\mathrm{M}_{\mathrm{H}}$ values. The maximum torque value of a compound is an indication of degree of cure attained in a vulcanizate and the nature of polymer - filler, filler - filler interactions in a cured compound. The results thus show that $5 \mathrm{phr}$ NC provides the optimum polymer-filler interactions and further increase in the $\mathrm{NC}$ loading leads to the filler agglomeration and weak filler - filler interactions [26]. Figure 2 shows the effect of storage time on the cure properties of the nanocomposites. From the Figure 2, it is clear that the shelf life of the compound is very less and studies showed that the compound should be consumed within 3 days of mixing. The deciding factor which decides the scorch safety and shelf life is the addition of $\mathrm{ZnO}$. The XNBR manufacturers recommend the storage of XNBR compounds without $\mathrm{ZnO}$ and addition of $\mathrm{ZnO}$ towards the end of mixing. As carboxylated acrylonitrile butadiene rubber (XNBR) is a terpolymer composed of acrylonitrile, butadiene and monomers containing carboxyl groups, such as acrylic and methacrylic acids. XNBR contains different active functional groups, including nitrile groups $(-\mathrm{CN})$, carboxylic groups $(-\mathrm{COOH})$, and alkene groups. All of these groups can participate in the crosslinking reaction, leading to the formation of different types of bonds, mainly covalent and ionic. Lateral carboxyl functionalities - $\mathrm{COOH}$ provide additional curing sites and make possible to use curing agents that can react with them contributing to the formation of ionic bonds. The conventional curing agents for XNBR that lead to ionic crosslinks are generally based on salts and oxides of multivalent metals (e.g., $\mathrm{ZnO}$, $\mathrm{MgO}, \mathrm{CaO}$ ), where the crosslinking reaction occurs through the formation of the corresponding salt of the metal ion [31]. 
Table 1. Cure characteristics of XNBR nanocomposites

\begin{tabular}{|c|c|c|c|}
\hline Composition & Scorch time & OCT (min) & $\begin{array}{c}\text { Maximum } \\
\text { torque (Kg-cm) }\end{array}$ \\
\hline XHAF 20 & 9.8 & 23.5 & 15.3 \\
\hline XNC 2.5 & 9.1 & 22.5 & 16.9 \\
\hline XNC 5 & 8.5 & 20.3 & 19.6 \\
\hline XNC 10 & 7.6 & 17.9 & 17.6 \\
\hline
\end{tabular}

(Note: OCT - Optimum cure time)

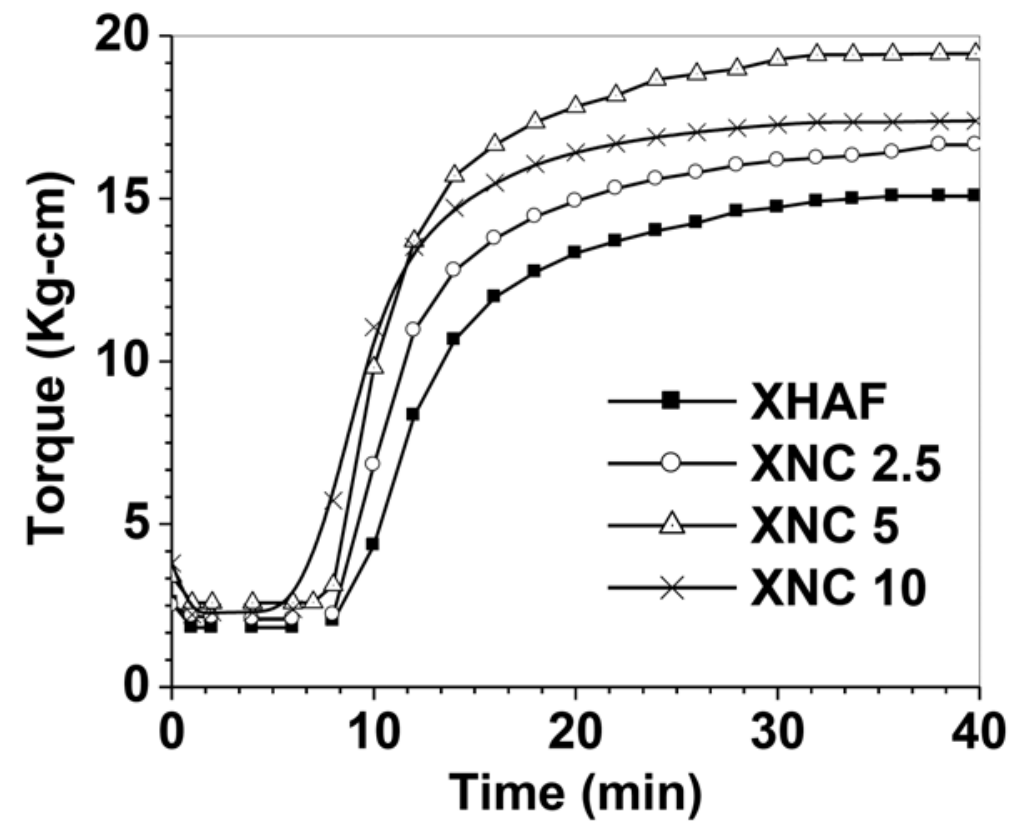

Figure 1. Rheometer curves for XNBR nanocomposites. 


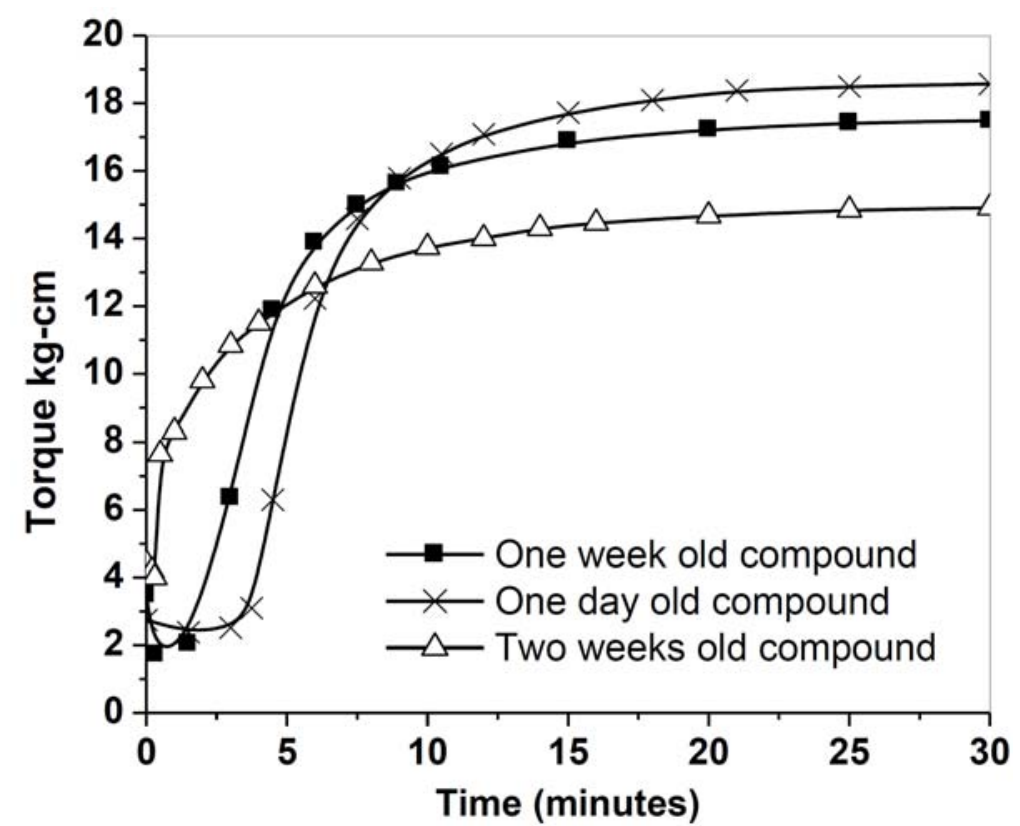

Figure 2. Effect of storage time on cure behaviour of XNBR nanocomposites.

\section{Wide angle XRD studies}

The XRD scans of the XNBR nanocomposites are shown in Figure 3. The clay shows $d_{100}$ peak at $2 \theta=3.9$ which corresponds to a $d$-spacing of $2.26 \mathrm{~nm}$. This indicates that modification of clay with organic ions, not only makes the clay surface hydrophobic but results in tremendous increase in $d$-space ( $d$-space for untreated clay $<1 \mathrm{~nm}$ ), which facilitates the penetration of liquid resin into the interlayer galleries [27]. For the nanocomposites prepared, the $d_{001}$ peak corresponding to pristine organoclay shifted to higher angle corresponding to a $d$-spacing of $1.5 \mathrm{~nm}$ which is lower than that of pristine organoclay. Generally, in case of intercalated nanocomposites, the peak appears at lower angle corresponding to higher $d$-spacing. However, this unusual behaviour was also reported by Karger-Kocsis and Wu [8]. They have attributed the higher angle shifts in XRD peaks to the partial removal (extraction) of 
the amine compound from the inter-gallery region, which might have participated in the complex formation (during vulcanization), leading to the collapse of that portion of the organoclay. This was attributed to the collapsing of clay layers due to the high compressive stress occurring during two-roll mill processing.

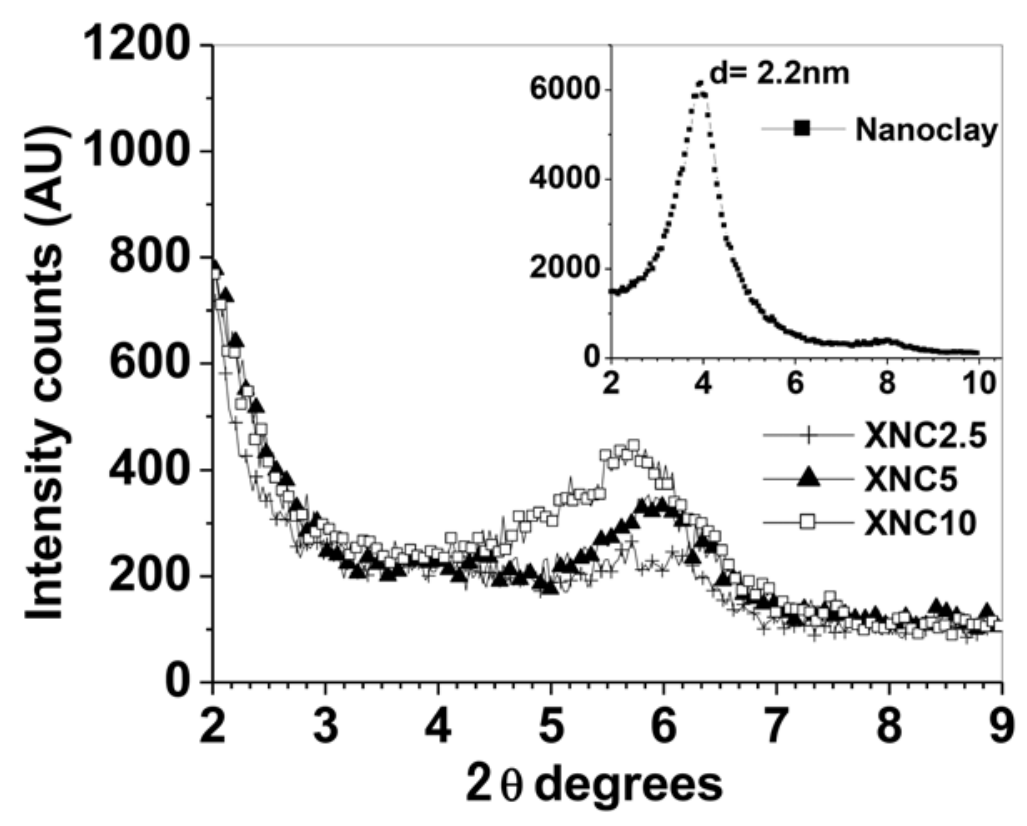

Figure 3. XRD behaviour of XNBR nanocomposites.

\section{Morphology using TEM}

In order to get better insight into the nanocomposites structure, selected samples were characterized by TEM. TEM photomicrographs for rubber nanocomposites with $10 \mathrm{phr} \mathrm{NC}$ is presented in Figure 4. It is clear that the nanocomposites prepared show a mixed morphology of intercalated and exfoliated clay structures. 


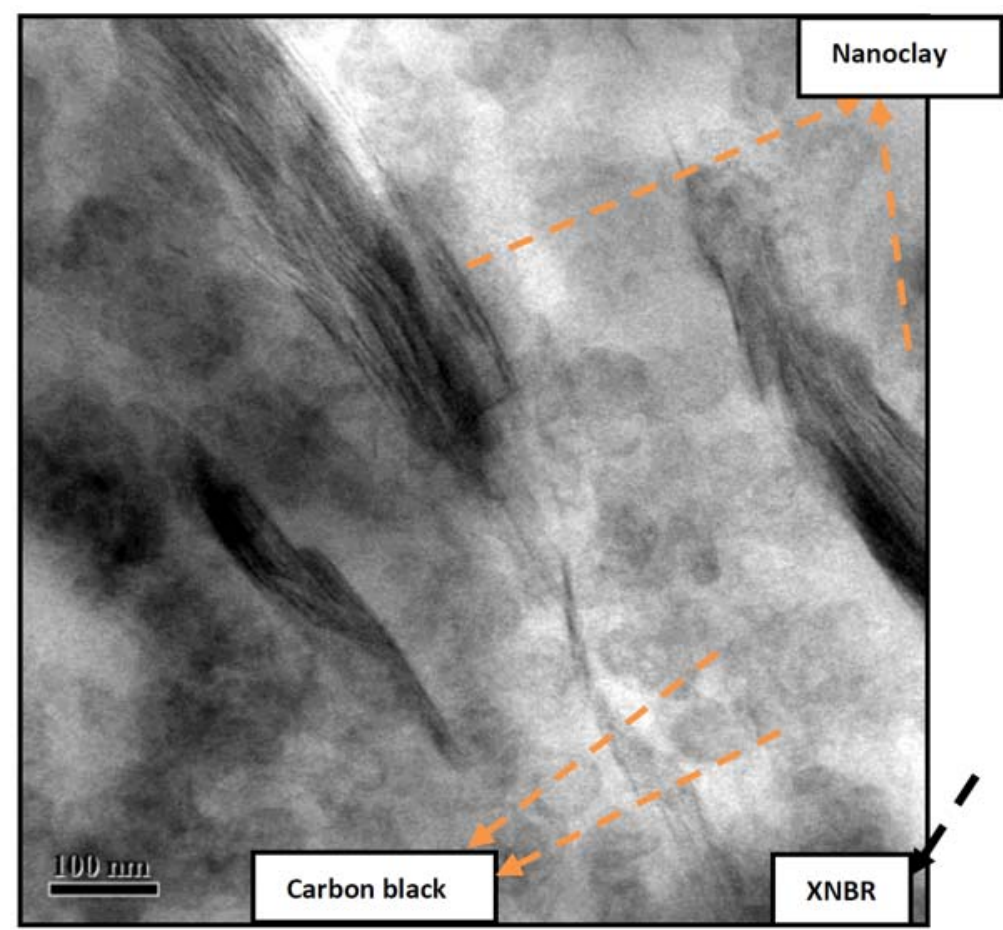

Figure 4. TEM photomicrograph of XNBR nanocomposites.

\section{Mechanical properties}

Tensile properties of the rubber nanocomposites are presented in Table 2. Nanoclay was added to XHAF 20 in the range of 2.5 to $10 \mathrm{phr}$. As depicted by Table 2 , the tensile strength of XNBR HAF 20 increased with the addition of $2.5 \mathrm{phr}$ NC. XNC 2.5 showed maximum tensile strength and elongation at break. The increase in strength is attributed to the synergistic effect between carbon black and nanoclay [12]. In general, increase in reinforcement is associated with a decrease in ultimate elongation. However, this is not always the case with organoclaymodified rubbers. Karger-Kocsis and $\mathrm{Wu}$ [8] speculated that the unexpected high elongation in rubber nanocomposites is likely due to the encapsulation of individual clay layers and tactoids in a more crosslinked rubber fraction than the bulk itself. As a consequence, the less crosslinked portion of rubber contributes more towards the deformation 
of the rubber matrix resulting in higher percentage in elongation at break. As the NC loading was increased from 2.5 to 5 and 10phr the tensile strength and elongation at break decreased. The strength decreases owing to the agglomeration of NC platelets, which form weak points in the matrix. The TEM photomicrograph clearly shows the formation of $\mathrm{NC}$ agglomerates.

Table 2. Tensile properties of XNBR - nanocomposites

\begin{tabular}{|c|c|c|c|c|}
\hline Composition & $\begin{array}{c}\text { Tensile } \\
\text { strength } \\
\mathrm{MPa}\end{array}$ & $\begin{array}{c}\text { Elongation at } \\
\text { break \% }\end{array}$ & $\begin{array}{c}\text { Stress at 100\% } \\
\text { elongation } \\
\text { (MPa) }\end{array}$ & $\begin{array}{c}\text { Stress at 300\% } \\
\text { elongation } \\
\text { (MPa) }\end{array}$ \\
\hline XHAF 20 & 10.9 & 374 & 2 & 7.4 \\
\hline XNC 2.5 & 17.7 & 464 & 2.1 & 7.8 \\
\hline XNC 5 & 15.7 & 441 & 2.4 & 8 \\
\hline XNC 10 & 9.8 & 359 & 2.5 & 7.7 \\
\hline
\end{tabular}

\section{Dynamic mechanical analysis}

DMA is an effective tool for obtaining some indirect evidence on the dispersion of the layered silicate [28-30]. In dynamic-mechanical measurements, the storage modulus and $\tan \delta$ for the filled samples are obtained and plotted against the temperature. The effect of $\mathrm{NC}$ on the dynamic properties of XHAF 20 is shown in Figure 5 and Figure 6 . The storage modulus increased with increase in the $\mathrm{NC}$ loading. The modulus increased from 5MPa (for XHAF 20) to 9MPa (for XNC 10). At above glass transition temperature the storage modulus increases in the case of XHAF 20 and XNC 10 because filler, nanoclay restricts the segmental motion of neat rubber which enhances the storage modulus significantly. This indicates that nanoclay is more efficient in reinforcing rubber. Similar observation was reported by Ratna for epoxy/clay systems [1, 2]. The $\tan \delta_{\max }$ values decreased from 1.4 to 1.18 for XNC 10 and peak shifts towards the higher temperature in case of nanoclay loaded rubber which indicates restriction of chain segmental motion of rubber by nanoclay. This can be attributed to the increase in stiffness resulting from nanoclay incorporation [29]. 


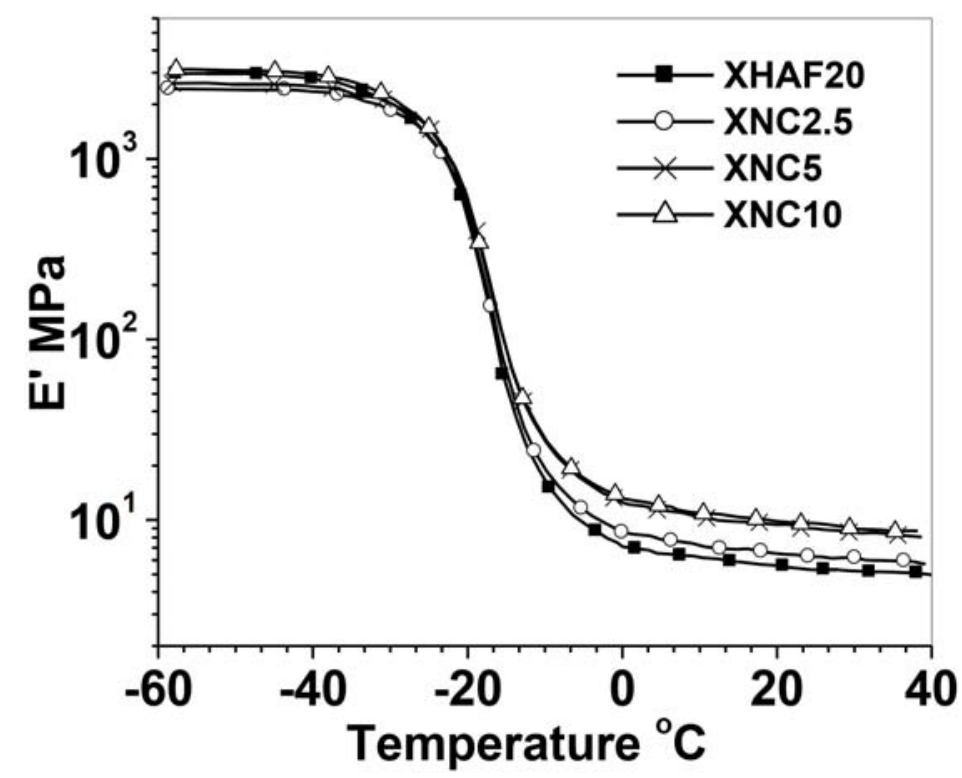

Figure 5. Storage modulus as a function of temperature for XNBR nanocomposites.

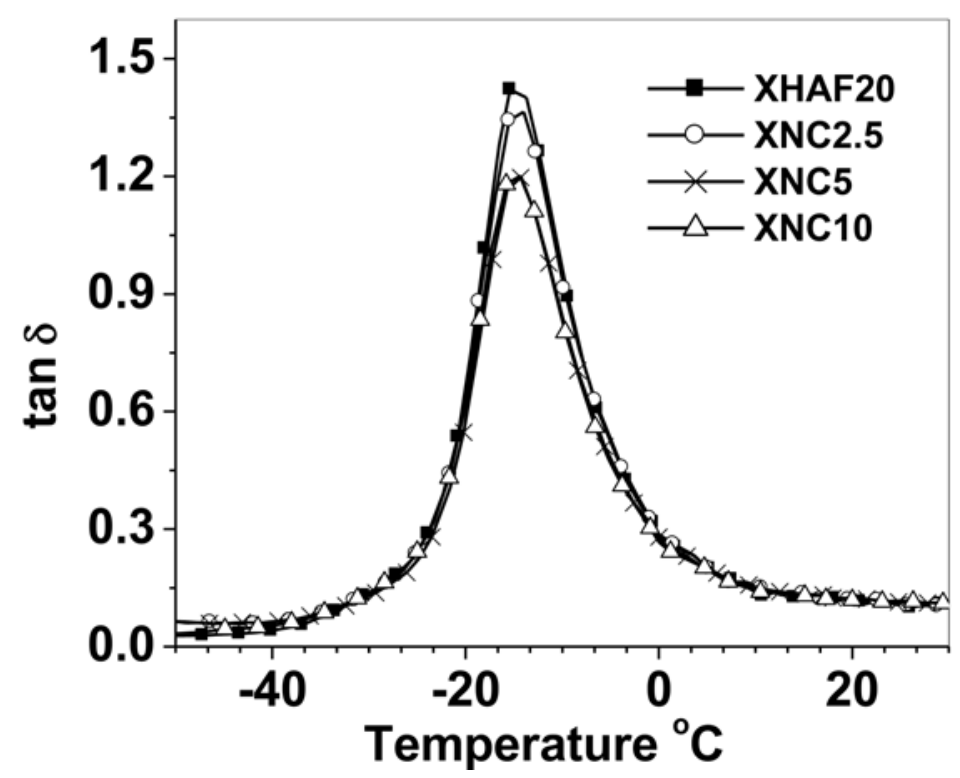

Figure 6. $\tan \delta$ as a function of temperature for XNBR nanocomposites. 


\section{Conclusion}

Preparation and processing of XNBR nanocomposites was studied. The addition of $\mathrm{NC}$ accelerated the curing of the rubber composite. Scorch safety and shelf life of XNBR nanocomposites was affected considerably by the presence of $\mathrm{ZnO}$. Curing the rubber composites at lower temperatures yielded optimum physical properties. XRD analysis reveals that NC showed additional peaks towards higher angles suggesting the layer collapse. This layer collapse was explained by considering the high compressive stress encountered by the clay layers while processing in two roll mill. TEM analysis indicates a mixed morphology of intercalated and exfoliated structures for nanocomposites. XNC 2.5 showed maximum tensile strength and elongation at break. The increase in strength is attributed to the synergistic effect between carbon black and nanoclay. As the NC loading was increased from 2.5 to $10 \mathrm{phr}$ the tensile strength and elongation at break decreased. The strength decreases owing to the agglomeration of $\mathrm{NC}$ platelets, which form weak points in the matrix.

\section{Acknowledgements}

The authors are thankful to Dr. P. Thavamani and Dr. K. Rajkumar for providing facilities at IRMRA Laboratory.

\section{References}

[1] D. Ratna, Handbook of Thermoset Resins, Smithers Rapra Technology, London, U.K., 2009.

[2] D. Ratna, Rapra Review Report 16(5) (2005), 1.

[3] J. Jordan, I. K. Jacob, R. Tannenbaum, M. A. Sharaf and I. Jasiuk, Materials Science and Engineering A 393 (2005), 1.

[4] S. Sinha Ray, J. Ind. Eng. Chem. 12 (2006), 811.

[5] Y. T. Vu, J. E. Mark, L. H. Pham and M. Engelhardt, J. App. Polym. Sci. 82 (2001), 1391.

[6] S. Sadhu and A. K. Bhowmick, Rubber Chem. Technol. 76 (2003), 86.

[7] S. Sadhu and A. K. Bhowmick, J. Appl. Polym. Sci. 92 (2004), 698. 
[8] J. Karger-Kocsis and C.-M. Wu, Polym. Engg. Sci. 44 (2004), 6.

[9] H. Akita and T. Hattori, J. Polym. Sci. B: Polym. Phys. 37 (1999), 189.

[10] J. W. Cho and D. R. Paul, Polymer 42 (2001), 1083.

[11] M. Maiti, S. Sadhu and A. K. Bhowmick, J. Appl. Polymer Science 96 (2005), 443.

[12] S. Praveen, P. K. Chattopadhyay, P. Albert, V. G. Dalvi, B. C. Chakraborty and S. Chattopadhyay, Composites: Part A 40 (2009), 309.

[13] S. Praveen, P. K. Chattopadhyay, S. Jayendran, B. C. Chakraborty and S. Chattopadhyay, Polymer Composites 3 (2009), 97.

[14] H. R. Dennis, D. L. Hunter, D. Chang, S. Kim, J. L. White, J. W. Cho and D. R. Paul, Polymer 42 (2001), 9513.

[15] T. D. Fornes, P. J. Yoon, H. Keskkula and D. R. Paul, Polymer 42 (2001), 9929.

[16] S. Sinha Ray and M. Okamoto, Prog. Polym. Sci. 28 (2003), 1539.

[17] M. Alexandre and P. Dubois, Mater. Sci. Eng. Reports 28 (2000), 1.

[18] M. Biswas and S. Sinha Ray, Advances in Polymer Science 155 (2001), 167.

[19] A. D. Roberts, eds., Natural Rubber Science and Technology, Oxford Sci. Publ., Oxford, 1990.

[20] M. Ganter, W. Gronski, H. Semke, T. Zilg, C. Thomann and R. Mülhaupt, Kautschuk Gummi Kunststoffe 54(4) (2001), 166-171.

[21] M. Ganter, W. Gronski, P. Reichert and R. Mülhaupt, Rubber Chem. Technol. 7 (2001), 221.

[22] M. Pramanik, S. K. Srivastava, B. K. Samantaray and A. K. Bhowmick, J. Appl. Polym. Sci. 87 (2003), 2216.

[23] Y. Wang, L. Zhang, C. Tang and D. Yu, J. Appl. Polym. Sci. 78 (2000), 1879.

[24] A. Mousa and J. Karger-Kocsis, Macromol. Mater. Engg. 286 (2001), 260.

[25] F. Schon, R. Thomann and W. Gronski, Macromol. Symp. 189 (2002), 105.

[26] R. Rajasekar, P. Kaushik, G. Heinrich, A. Das and C. K. Das, Materials and Design 30 (2009), 3839.

[27] S. Varghese, J. Karger-Kocsis and K. G. Gatos, Polymer 44 (2003), 3977.

[28] S. Varghese, K. G. Gatos, A. A. Apostolov and J. Karger-Kocsis, J. Appl. Polym. Sci. 92 (2004), 543.

[29] F. Schön and W. Gronski, Kautschuk Gummi Kunststoffe 56 (2003), 166.

[30] H. B. Lu and S. Nutt, Macromolecules 36 (2003), 4010.

[31] A. Laskowska, M. Zaborski, G. Boiteux, O. Gain, A. Marzec and W. Maniukiewicz, Express Polymer Letters 6 (2014), 374. 